\title{
Margaret McCartney: For better primary care, pay GPs for service
}

\author{
Margaret McCartney general practitioner, Glasgow
}

How should GPs be paid: by item, or for service? Currently, it's per item, through micromanagement. Not per appointment but by ticking boxes: smoking or not, cardiopulmonary resuscitation or not, blood pressure target or not.

But the box may not represent anything useful, appropriate, or kind. Say "every contact counts," and repeat the mantra "GPs are ideally placed to ..."-whether evidence based or not.

When GPs achieve many ticks, up the ante: make the hoops smaller and higher. Add items that have not been proved to cut unnecessary admissions or to reduce wasted drugs or identify future suicide bombers.

Add accountability - to the Care Quality Commission, contract inspections, commissioning units, patients, and the General Medical Council. Meanwhile, defund social care, wear down district nurses, and allow mental health services to exist in a twilight of waiting lists and CBT-lite.

Then conclude that general practice is failing. Encourage patients to switch GPs on the basis of unverified online reviews. Suggest competition and privatisation as a solution to the created problem. Game contracts, and make patients feel as though they are on a production line. Conclude that GPs cannot be trusted. Increase micromanagement. And repeat.

But there is another way. Forget the current contract. Pay for service, and work out what that should be. Recruit primary care staff for their vocation and intelligence. Let them organise themselves, floridly, nakedly, contract-less. Stop mere short term goals, and talk about the meaning of a 30 year career.
Prioritise relationships with patients, carers, and colleagues in social and mental health and secondary care. Talk about what we should do and how. Ask what we need to help achieve it.

Collect data of importance to patients and doctors. Free GPs and nurses from the shackles of the computer tick box. Allow conversations to flow. Be open about everything that doesn't need confidentiality. Discuss data, but never allow unsafe conclusions. Don't subject staff or patients to guidelines without a decision aid and a number needed to treat or harm.

Acknowledge that a 10 minute consultation is not adequate, safe, or satisfying for most people, so stop doing things that don't work, and make time for longer ones. Recognise that doctors in deprived areas are under more pressure, and increase their resources.

How would we know whether this was better or worse? What outcomes would we compare? We could look for hard data on heart attacks, suicide, cancer diagnoses, and hospital admissions, but these will likely take years to show benefit or harm, and conclusions about trends related to contracts will never be definite.

Pay doctors for the time that they spend working, and support, rather than punish, practices that are not fulfilling their ambitions for themselves. It's time to give up itemised contracts and to start talking about vocation instead.

Cite this as: BMJ 2015;351:h4839

๑ BMJ Publishing Group Ltd 2015 